\title{
Effects of heat: UK exercise Saif Sareea 3 and interpreting military climatic guidance
}

\author{
Samuel White, ${ }^{1}$ M B Smith ${ }^{2}$
}

${ }^{1}$ Royal Centre for Defence Medicine, Queen Elizabeth Hospital Birmingham, Birmingham, UK

${ }^{2} 5$ Armoured Medical Regiment, British Army, Catterick Garrison, UK

\section{Correspondence to} M B Smith, Armoured Medical Regiment, British Army, Catterick Garrison, UK; drmike17@icloud.com

Received 29 October 2019 Revised 21 April 2020

Accepted 26 April 2020 Published Online First 19 May 2020

\section{Check for updates}

(c) Author(s) (or their employer(s)) 2020. No commercial re-use. See rights and permissions. Published by BMJ.

To cite: White S, Smith MB. BMJ Mil Health

2020;166:401-405.

\section{ABSTRACT}

Introduction Over recent years much research, both civilian and military, has occurred in the field of heat illness. This has helped force health protection and medical management of service personnel operating in hot climates. Exercise Saif Sareea 3 in Oman saw a collection of presentations to the deployed UK medical treatment facilities due to the effects of heat.

Method This paper aims to describe the case series of 24 casualties that presented to the deployed primary care facilities and 17 that were admitted to the deployed secondary care facility due to the effects of heat.

Results Only 10 casualties fulfilled the in-theatre diagnostic criteria for heat illness, of which two were of moderate severity and required aeromedical evacuation to the UK.

Conclusions Commanders appeared extremely well read on Joint Service Publication 539 (JSP539; May 2017) Heat IIIness and Cold Injury: Prevention and Management, following the Brecon enquiry, and were proactive in managing their force in preventative measures. This likely contributed towards the low numbers of patients with heat illness seen on the exercise. JSP539 did, however, appear to have some limitations when trying to apply it to all patients seen within the operational patient care pathway, and some areas for development are discussed.

\section{INTRODUCTION}

In 1989, The Times published a letter by Sir Roger Bannister stating, 'The notion that courage and esprit de corps can somehow defeat the principles of physiology is not only wrong but dangerously wrong.' History has shown the British Army learning this the hard way, with operations to hot climates ending in disaster due to heat rather than enemy action. ${ }^{1-3}$ In the late 20th century, building on research and observations from previous decades, the military began to see improvements in these statistics, largely through improved heat acclimatisation training.

During exercise Saif Sareea 3 (SS3) Joint Service Publication 539 (JSP539) May $2017^{5}$ was the most up-to-date iteration of defence policy on prevention and management of heat illness in UK service personnel (SP). It defines heat illness as 'individuals who become incapacitated as a result of a rise in core body temperature' but acknowledges that heat illness is a spectrum and can be difficult to distinguish between conditions due to the many possible presenting symptoms as seen in Table 1 taken from JSP539.

The JSP is intended as a point of reference whenever soldiers are undertaking strenuous physical

\section{Key messages}

- Commanders following Joint Service Publication 539 guidance on training in hot environments likely helped to produce a lower than expected heat illness casualty rate on exercise Saif Sareea 3.

- When operating in a hot climate it can be difficult to differentiate heat illness from dehydration and salt loss.

- Half of the confirmed heat illness casualties were of the non-exertional type.

- Additional prehospital methods of cooling have potential to be expanded and used in future operations.

activity, be that in the UK or overseas. The document aims to educate commanders and defence medical personnel in an attempt to stop perceived preventable morbidity and mortality attributed to heat in soldiers as was seen in the Brecon Beacons, Wales, July 2013. During a military exercise a number of soldiers succumbed to exertional heat illness due to the demanding physical nature of the exercise and the prevailing temperatures. Two soldiers died that day and a third 2 weeks later in hospital. There were a further eight heat illness casualties of which three were hospitalised after the event. Recommendations from the Service Inquiry into this event published in April $2017^{6}$ were included in the JSP539.

Once a military casualty enters the operational patient care pathway, early recognition, correct diagnosis and appropriate treatment of the effects of heat are of paramount importance. This helps limit morbidity and ensures that appropriate follow-up is arranged. It also allows timely and correct identification of evolving trends within theatre which can be notified to Commander Medical. Unfortunately, over the years, many different definitions have been proposed and used to describe those that suffer from the effects of heat. ${ }^{7-9}$ This can make communication about cases difficult and data collection complex to interpret, especially outside of the Defence Medical Services.

Exercise SS3 was the largest joint and combined British military exercise for over 17 years. It involved large-scale, long-distance armour and armoured infantry manoeuvre and live firing in the Omani desert in October 2018, although troops were in Oman from July until December. The peak temperatures experienced were in excess of $50^{\circ} \mathrm{C}$. The maximum population at risk during SS3 was 


\begin{tabular}{lll}
\hline \multicolumn{2}{l}{ Table 1 Signs and symptoms of heat illness } \\
\hline $\begin{array}{l}\text { Inappropriate or unusual } \\
\text { behaviour }\end{array}$ & Confusion & Disturbed vision \\
\hline Anxiety and/or agitation & Paraesthesia & Headache \\
\hline Impaired judgement & Hyperventilation & Dizziness \\
\hline Staggering or loss of coordination & Myalgia, cramps or tetany & Weakness or fatigue \\
\hline Collapse or loss of consciousness & Seizure(s) & Nausea \\
Vomiting & Diarrhoea & Thirst \\
\hline
\end{tabular}

5500 UK troops across a large geographic area, with the main body at Camp Shafa. Accommodation was in 9-person cabins, 100 -person transit tents, both air conditioned, or in field conditions.

Casualties could present to either the UK Role 2 at Camp Shafa which was the deployed secondary care hospital facility, or to any one of a number of UK Role 1 locations, which were the deployed primary care facilities. Once casualties presented themselves, JSP539 was used as a reference document to aid both their immediate management and ongoing treatment. While JSP539 is primarily for prehospital emergency care, section 2, especially annex B 'exertional heat illness treatment guidelines Role 1 and Role2/3' is useful and perhaps more in-depth than current Clinical Guidelines for Operations. ${ }^{10}$ While deployed on SS3, further guidance was provided and distributed to medics in the field in the form of an exercise-specific Heat Injury Immediate Actions Drill which used the 'instant' ice packs and spray/ fans. Also, the additional cooling methods were discussed in Heat Injury teaching with the deployed Role 1 medical staff by the Brigade Senior Medical Officer (SMO).

JSP539 focuses on exertional heat illness, whereas a number of casualties appeared to present with the effects of heat while not heavily exerting themselves, so called non-exertional, or classical heat illness. Also, some casualties were felt to have symptoms due to the effects of operating in a hot environment but not due to heat illness and with no suggestion of a period of elevated core body temperature. Acknowledging the concern about true heat illness casualties within the higher (non-medical) command chain on SS3 it was decided case definitions should be confirmed to reduce the chance of miscommunication and to attempt to instil uniformity across the medical teams deployed. Therefore, the SMO, Deployed Medical Director (DMD) and Deployed Consultant Physician proposed diagnostic classifications (below) with remote input from the Institute of Naval Medicine (INM). Regular communication between the deployed Consultant Physician, Brigade SMO, Brigade Commander and Chief Medical Officer allowed real-time courses of action to be initiated.

Heat illness: SP presenting with an elevated core temperature (or who is suspected of having an elevated core temperature prior to the initiation of prehospital cooling) who has symptoms of heat illness (Table 1). If the onset of symptoms bears a close relationship to exercise, then it should be classified as exertional heat illness. Those not associated with exercise should be classified as non-exertional heat illness. Given the military setting exertional and non-exertional should be used rather than exertional and classical. The severity of heat illness remained as per JSP539 (Table 2).

With reference to previous categories (heat exhaustion and heat stroke), patients with mild heat illness and most of those with moderate heat illness could be thought of as having heat exhaustion. Heat stroke, traditionally defined as those with a core temperature above $40^{\circ} \mathrm{C}$ and central nervous system

\section{Table 2}

\begin{tabular}{ll}
\hline Severity of heat illness \\
\hline Mild & $\begin{array}{l}\text { May require admission but NO signs of biochemical derangement, } \\
\text { rhabdomyolysis or CNS disturbance* }\end{array}$ \\
Moderate & $\begin{array}{l}\text { Requires admission AND has: } \\
\text { evidence of biochemical derangement OR } \\
\text { rhabdomyolysis OR } \\
\text { CNS disturbance* }\end{array}$ \\
Severe & Requires admission to the ICU
\end{tabular}

${ }^{*}$ CNS disturbance-seizure OR GCS less than 8/15 for greater than 15 min. CNS, central nervous system; ICU, intensive care unit.

disturbance, would most likely cover those patients with severe heat illness. Those who presented with symptoms but felt not to meet the definitions above included:

Exertional heat syncope: SP who collapses with transient loss of consciousness during, or shortly after exercise, with no evidence of elevated core temperature (or suspicion of elevated core temperature). The mechanism of collapse is likely being related to dilatation of blood vessels during exercise in hot climates and subsequent reduction in BP that can occur. These casualties were assessed and some required admission to rule out other more sinister causes of exertional syncope.

Hyponatraemialdebydration: SP who presented unwell and was found, following examination and investigations, to have evidence of dehydration, with or without hyponatraemia. This has been noted to be a common presentation in hot climates due to excess sweating and insufficient replacement of fluids and salts. This syndrome presents similar to heat illness and the diagnosis can be difficult to distinguish. This occurred more frequently in the acclimatisation phase of the deployment while soldiers sweat mechanisms adapted to the hot environment. This is similar to previous experience of trends in presentation to deployed medical treatment facilities. ${ }^{11}$

Hyponatraemia (fluid overload): SP who presents with symptoms of dizziness, confusion, lethargy and fatigue which may be due to water toxicity. ${ }^{12}$ In some cases it can be difficult to distinguish from heat illness (Table 3). This can be a life-threatening condition and needs quick and appropriate treatment. There was concern about the possibility of these cases presenting due to reports of water parades within some units where SP were encouraged to drink large volumes of fluid. The misconception that this would prevent them succumbing to heat illness. This was addressed early on via education through the chain of command.

The aim of this paper is therefore to describe the case series which presented to the UK deployed medical treatment facilities as well as a breakdown of individual patient demographics in order to learn from them and how JSP539 was interpreted.

\section{METHODS}

Data were collected prospectively on patients admitted due to the effects of heat to the UK Role 1 Medical Reception Station (MRS) and the UK Role 2 both located at Camp Shafa. Data were collected retrospectively on patients who were aeromedically evacuated from the training area to a host nation facility in Muscat or other UK Role 1 facilities. Patient data were entered onto a secure live MS Excel spreadsheet allowing monitoring of the numbers of heat casualties in real time. Data collected on each casualty included basic demographics such as age and sex. For those categorised as heat illness we also collected data on known risk factors where possible. This included: smoking status, body mass index (BMI), most recent personal fitness assessment time, number of 
Table 3 Differentiation between heat illness and fluid overload/ water toxicity

\begin{tabular}{lll}
\hline & Heat illness & Fluid overload \\
\hline Core temperature rise & In severe cases & Uncommon \\
\hline Resting pulse rate & Elevated & Normal \\
\hline BP & Hypotensive or normal & Normal or elevated \\
\hline Orthostatic change in BP & Decrease & No decrease \\
\hline Urine output & Oliguric & Polyuric \\
History of fluid intake & Varied & Usually increased \\
Response to cooling & Gradual recovery & No improvement \\
CNS disturbance & In severe cases & Common \\
Mucosa & Usually dry & Moist \\
$\begin{array}{l}\text { Symptoms and signs } \\
\text { common with both } \\
\text { conditions }\end{array}$ & $\begin{array}{l}\text { Nausea and vomiting, fatigue, headache and dizziness, } \\
\text { disorientation, confusion, ataxia, seizures }\end{array}$ \\
\hline
\end{tabular}

CNS, central nervous system.

days in Oman, if acclimatisation had been undertaken, as well as activity undertaken, and clothing worn at time of presentation. Finally, data were collected on presenting signs and symptoms including initial temperature taken prehospital and route by which assessed (tympanic or rectal), observations including GCS and initial blood results. All of the above was part of the routine care given to patients and data collection for reporting as per directions from JSP539.

\section{RESULTS}

Twenty-four patients presented to the MRS with symptoms which could be consistent with heat illness. All were assessed by a medical officer and thought to be suffering due to mild dehydration. None had a documented elevated core temperature or suspicion of previously elevated core temperature after history and examination was undertaken. Two of the 24 were referred onwards to the Role 2 for further assessment. In both cases the initial diagnosis of dehydration was confirmed, with no sign of end organ damage seen on blood investigations.

Seventeen patients presented to the Role 2 due to the effects of heat. Ten of the 17 (59\%) fulfilled the in-theatre diagnostic criteria for heat illness of which nine were male. Of the 10 diagnosed at Role 2 as having heat illness, the average age was 26.9 years (range 18-42 years), four (40\%) were smokers and mean BMI was
$26.1 \mathrm{~kg} / \mathrm{m}^{2}$. Two (20\%) were taking medications known to reduce tolerance to the heat (antihistamine and antibiotics). One of the 10 patients with heat illness overflew the Role 2 by the Medical Emergency Response Team en route to a host nation facility hospital (tertiary care hospital) in Muscat. They were later assessed at the Role 2 and diagnosed as mild non-exertional heat illness, although they did not require admission, but due to the development of phlebitis which was slow to resolve they were aeromedically evacuated to the UK. The other nine (90\%) patients with heat illness were all admitted to the Role 2. Data from these 10 patients with heat illness can be seen in Table 4 .

Two (20\%) of the patients with heat illness were graded according to JSP539 as moderate heat illness and were aeromedically evacuated to the UK with recommendation that they should be referred by their Medical Officer to the heat injury clinic at the Institute for Naval Medicine.

No patient arrived at the MRS or Role 2 with an elevated core temperature. Three patients had a documented elevated core temperature prehospital when assessed by either a Combat Medical Technician, Nurse or General Duties Medical Officer. No patients were seen to have a seizure complicating their presentation. Three $(30 \%)$ had a GCS of 14 on admission due to confusion. One patient had cardiac arrhythmias (junctional rhythm and bundle branch block) although this was not life threatening, not haemodynamically significant and felt to be unrelated to the presentation. Targeted echocardiography performed at Role 2 showed no underlying structural heart disease. Two patients (20\%) required a period on intensive care unit (ICU) at Role 2, one due to reduced GCS (mild confusion) for a few hours and the other in order to receive intravenous potassium supplementation. Five $(50 \%)$ of the patients admitted to Role 2 and diagnosed with heat illness had onset of symptoms during exercise and as such graded as exertional heat illness. Of those patients returned to unit (RTU) in theatre to rejoin the exercise, none represented.

\section{DISCUSSION}

\section{Diagnosis}

Early in the exercise it became clear that casualties presenting due to the effects of heat were a heterogeneous group and clear case definitions and uniformity across the deployed medical force were required both for medical management and communication across the chain of command. On Operation TELIC 2 (Iraq 2003), approximately 300 SP were diagnosed with heat

\begin{tabular}{|c|c|c|c|c|c|c|c|c|c|c|c|}
\hline Patient & Activity & $\begin{array}{l}\text { Initial } \\
\text { temperature }\end{array}$ & $\begin{array}{l}\text { ED } \\
\text { temperature }\end{array}$ & $\begin{array}{l}\text { Initial } \\
\text { GCS }\end{array}$ & $\mathrm{Na}$ & K & $\mathrm{Cr}$ & CK & LFT & Diagnosis & Disposal \\
\hline 1 & L work & $37.1 r$ & $37.1 r$ & 14 & 132 & 3.8 & 88 & UA & $\uparrow$ & EHI & $\mathrm{AE}$ \\
\hline 2 & L work & $36.6 \mathrm{t}$ & $36.6 \mathrm{t}$ & 15 & 130 & 3.6 & 105 & UA & UA & NEHI & RTU \\
\hline 3 & L work & $37.0 \mathrm{t}$ & $37.0 \mathrm{t}$ & 15 & 126 & 3.7 & 299 & 1338 & $\uparrow$ & NEHI & $\mathrm{AE}$ \\
\hline 4 & PT & $37.5 t$ & $37.5 t$ & 15 & 142 & 4.1 & 123 & 113 & Normal & EHI & RTU \\
\hline 5 & H work & $38.1 r$ & $37.4 \mathrm{t}$ & 15 & 143 & 3.0 & 106 & 412 & Normal & EHI & RTU \\
\hline 6 & L work & $36.8 \mathrm{t}$ & $37.0 \mathrm{t}$ & 15 & 137 & 3.9 & 92 & 337 & Normal & NEHI & RTU \\
\hline 7 & L work & $38.6 r$ & $37.0 \mathrm{t}$ & 14 & 130 & 2.5 & 106 & 298 & Normal & NEHI & RTU \\
\hline 8 & PT & $37.6 r$ & $36.6 \mathrm{t}$ & 15 & 143 & 4.2 & 89 & 167 & UA & EHI & RTU \\
\hline 9 & Rest & $38.7 r$ & $37.7 \mathrm{t}$ & 15 & 137 & 3.7 & 97 & 136 & Normal & NEHI & $A E^{*}$ \\
\hline 10 & AFT & $37.4 \mathrm{t}$ & $37.4 \mathrm{t}$ & 14 & 141 & 4.0 & 88 & 155 & Normal & EHI & RTU \\
\hline
\end{tabular}

*Patient 9 aeromedically evacuated due to non-heat-related illness.

AE, aeromedically evacuated; AFT, Annual Fitness Test; CK, creatine kinase; Cr, creatinine; ED, emergency department; EHI, exertional heat illness; $H$, heavy; $K$, potassium; L, light; LFT, liver function test; Na, sodium; NEHI, non-exertional heat illness; PT, physical training; r, rectal temperature; RTU, returned to unit in theatre; t, tympanic temperature; UA, test not available. 
illness via the heat illness unit ${ }^{13}$ compared with less than 50 SP treated for heat illness at the Role 2 medical treatment facilities on exercise Saif Sareea II (SS2) Oman 2001, ${ }^{14}$ despite the population at risk during TELIC 2 being approximately one-fourth of the size of that on SS2. This large difference in incidence might suggest different definitions being used. JSP539 uses multiple wordings to describe similar pathology also accepting that it encompasses a spectrum. The same is true in the civilian literature. 'Heat illness' appears to incorporate heat cramp, exertional heat syncope, heat fatigue, dehydration, heat exhaustion and heat stroke (both classical and exertional), not all of which are due to a rise in core body temperature. As stated, heat illness can be difficult yet critical to differentiate from hyponatraemia due to fluid overload as the management is very different. Table 3 shows subtle differences between the two. Education on the risks of overhydration should not be ignored during predeployment training to a hot environment.

JSP539 grades patients with heat illness as mild, moderate or severe, stating the latter two require aeromedical evacuation to the UK and follow-up at INM. Mild cases may remain in theatre. It was felt there was a risk of a patient not being given the correct diagnosis, not being referred to INM and subsequently being re-exposed to environmental risk and succumbing with potentially significant morbidity or mortality which could have been prevented. It was for these reasons that the SMO, DMD and the consultant physician proposed the in-theatre diagnostic classifications used.

\section{Prehospital care}

That no patient arrived at either the Role 1 or Role 2 with an elevated temperature highlights the awareness and understanding among soldiers, team medics and Combat Medical Technicians of the Clinical Guidelines for Operations, Heat Injury Drill. ${ }^{15}$ However, it was felt the focus on evacuation may have missed the importance of active cooling measures that can be initiated in the field, thereby minimising the total time the casualty has with an elevated core temperature which is known to be a key contributor to poor prognosis in heat illness. ${ }^{16} 17$ The primary role of aggressive cooling is to get core temperature below $40^{\circ} \mathrm{C}$ within $30 \mathrm{~min}^{16}$ It has been suggested that 'cool first, transport second' should be the principle used to minimise time spent above this threshold temperature. ${ }^{17}$

Neither JSP539 nor Clinical Guidelines for Operations mention the use of cold intravenous fluids, ice packs or water immersion as a means of cooling. Cold water immersion (CWI) is superior to other cooling methods due to the conductive potential of water ${ }^{17} 18$ and cools four times more rapidly than air, such that water between $2^{\circ} \mathrm{C}$ and $14^{\circ} \mathrm{C}$ can achieve cooling of $0.20^{\circ} \mathrm{C} / \mathrm{min}$. If no rectal temperature monitoring is available in a forward location, CWI should be done for $20 \mathrm{~min}$ (aiming for $4^{\circ} \mathrm{C}$ reduction) or until the shivering reflex starts, ${ }^{19}$ although it should only be undertaken where there is no concern about airway, breathing or circulation.

Other cooling options in the field include total ice pack coverage, ice pack rotation of extremities or application to major arteries, spray and fan, wet sheet and fan, and the use of a helicopter downdraft for evaporative cooling. ${ }^{20}$ These methods can achieve between $0.04^{\circ} \mathrm{C}$ and $0.1^{\circ} \mathrm{C} / \mathrm{min}$ as a rate of cooling. ${ }^{17} 20$ Immersion in warm water $\left(26^{\circ} \mathrm{C}\right)$ has been found to achieve cooling of $0.1^{\circ} \mathrm{C} / \mathrm{min},{ }^{21}$ thus water immersion should not be dismissed simply because no cold water is available prehospital. While armoured vehicles hold refrigerators (in theory) where cold water can be stored, other field options are 'Instant' ice packs that can be carried, accepting there is a limit to size and weight in the dismounted role.

Consideration should be given to these methods of more aggressive active cooling which would require access to (preferably) cool water and field immersion options which currently exist in service (eg, using a vacuum stretcher), plus addition of spray bottles and chemical ice packs to module listings.

\section{Future strike operations}

Continued use of armour in extreme climates is likely to continue to result in non-exertional heat injury, and command awareness and mitigation is paramount to prevention. With future strike operations working at reach heat casualties may require prolonged field care. The principle of 'cool first, transport second' is paramount in a position where immediate evacuation off the battlefield is not always possible.

\section{Treatment within the Medical Treatment Facility}

As stated, no patient arrived at Role 1 or Role 2 with an elevated temperature due to heat illness, thus active cooling was not continued in order to avoid overshoot hypothermia. It should be noted that initially the solar effects on the treatment facility tentage overwhelmed the capability of the environmental control units (ECU) such that temperatures recorded by Environmental Health inside the medical facilities regularly exceeded $30^{\circ} \mathrm{C}$. Local purchase of civilian air-conditioning units rectified this quickly but highlighted the issue that in-service ECUs can struggle in very hot deployments in their current ratio of units to square metres of tentage.

Emergency department and ward modules allowed for effective management of the patients. JSP539 dictates that patients require regular blood tests, including: full blood count, renal function, liver function, creatine kinase, blood glucose, serum osmolality and coagulation screen, as well as urinalysis, in order to assess for signs of end organ damage. This was labour and resource intensive and required a good working relationship with laboratory staff as well as ongoing planning to ensure adequate stocks of reagents were available.

Laboratory results (Table 4) highlighted the derangement of biochemical parameters, some of which required correction and in the case of intravenous potassium replacement this required use of the ICU. For oral correction it required a work around as no Sando-K or equivalent was not on the module lists. Although not required, it was noted that stocks of hypertonic saline for treatment of severe hyponatraemia were low. Perhaps medical modules could be reviewed in order to ensure treatment of these patients is possible, especially when deploying to a hot climate.

Once a diagnosis had been confirmed, disposal of the patient was relatively straightforward, be it aeromedical evacuation to the UK or return to unit (RTU) in theatre. The latter did pose problems in terms of what postdischarge rehabilitation needed to be undertaken prior to safe deployment back into the training serials. It was our opinion that guidance on this within JSP539 was limited and open to clinician interpretation. This was especially the case when the patient concerned had been admitted due to non-exertional heat illness. Our management can be seen in an accompanying paper in this supplement. Needless to say, no patient represented once discharged.

\section{CONCLUSIONS}

The effects of heat on SP operating and exercising in hot climates have continued to present issues to both commanders at all levels, and the deployed Defence Medical Services. The 
small numbers of patients seen on SS3 suggest that policy, education and interventions are working, and this should be acknowledged. However, we believe consideration should be given to the prehospital section of the casualty pathway in terms of the priority of cooling versus need to evacuate, although the operating and exercising environment will vary. Medical management at Role 1 and Role 2 continues to be appropriate as long as the resources are there to enable the clinicians. While we felt no patient had below standard care during the exercise, if we had seen the anticipated number of heat casualties presenting they could have easily outstripped our capability.

Our observations of the heterogeneous nature of the patients presenting suggest that JSP539 may benefit from some revision in the area of diagnostic definitions and non-exertional heat illness as well as in-theatre rehabilitation before returning to the exercise. This may offer an area for future research interest.

Contributors SW and MBS: drafting, researching and writing of the manuscript.

Funding The authors have not declared a specific grant for this research from any funding agency in the public, commercial or not-for-profit sectors.

Competing interests None declared.

Patient consent for publication Not required.

Ethics approval Observational study of normal records with no patient identifiable data.

Provenance and peer review Not commissioned; externally peer reviewed.

Data availability statement Data are available upon reasonable request. All data are held at 5AMR and are available on reasonable request to the authors.

\section{REFERENCES}

1 Stewart W. Effects of heat with special reference to its occurrence in British troops in the Persian Gulf area in 1941-42. J R Army Med Corps 1948;90:178-93.

2 Mitchell TJ, Smith GM. Medical services, history of the great war. Casualties and Medical Statistics, London: HMSO, 1931.
3 Mellor WF. Casualties and medical statistics. In: Official medical history of the second World War. London: HMSO, 1972

4 Whelan TR. Lands of contrast - Soldiering abroad: discussion paper. J R Soc Med 1988:81:721-2.

5 Ministry of Defence. Vol 3.0. Joint service publication 539: heat illness and cold injury prevention and management, 2017.

6 Releasable extracts of service enquiry into the death of 3 soldiers in the Brecon beacons Wales in July 2013, 2017. Available: www.gov.uk

7 Day TK, Grimshaw D. An observational study on the spectrum of heat-related illness, with a proposal on classification. J R Army Med Corps 2005;151:11-18.

8 Dickinson JG. Heat illness in the services. J R Army Med Corps 1994;140:7-12.

9 Yamamoto T, Fujita M, Oda Y, et al. Evaluation of a novel classification of heat-related illnesses: a multicentre observational study (heat stroke study 2012). Int I Environ Res Public Health 2018;15:1962.

10 Management. Ministry of Defence (UK). Joint service publication 999: clinical guidelines for operations, 2020.

11 Grainge $\mathrm{C}$, Heber M. The role of the physician in modern military operations: 12 months experience in southern Iraq. J R Army Med Corps 2005;151:101-4.

12 Shopes EM. Drowning in the desert: exercise-induced hyponatremia at the grand canyon. J Emerg Nurs 1997;23:586-90.

13 Bolton JPG, Gilbert PH, Tamayo C. Heat illness on operation Telic in summer 2003: the experience of the heat illness treatment unit in northern Kuwait. J R Army Med Corps 2006;152:148-55.

14 Bricknell MCM, Wright LA. EX SAIF SEREEA II--the field hospital clinical report. J $R$ Army Med Corps 2004;150:252-5.

15 Heat Illness. Treatment Guidelines Section 12. D. xxx in Joint Service Publication 999: Clinical Guidelines for Operations (2020). Management. Ministry of Defence (UK).

16 Pandoff KB, Burr RE. Medical aspects of harsh environments: 2. US: United States Government Publishing, 2002.

17 Casa DJ, McDermott BP, Lee EC, et al. Cold water immersion: the gold standard for exertional heatstroke treatment. Exerc Sport Sci Rev 2007;35:141-9.

18 McDermott BP, Casa DJ, Ganio MS, et al. Acute whole-body cooling for exerciseinduced hyperthermia: a systematic review. J Athl Train 2009;44:84-93.

19 Hosokawa Y, Adams WM, Stearns RL, et al. Heat stroke in physical activity and sports. Pensar en Movimiento: Revista de Ciencias del Ejercicio y la Salud, 2014.

20 Hadad E, Rav-Acha M, Heled Y, et al. Heat stroke : a review of cooling methods. Sports Med 2004;34:501-11.

21 Taylor NA, Casa DJ, Kenny GP. Immersion treatment for exertional hyperthermia; cold or temperature water? contrasting perspectives. Med Sci Sports Exer 2010;42:1246-52. 